\title{
Enquadres interativos e gestão do tópico discursivo em uma comunidade de práticas de afásicos e não afásicos
}

\author{
Caio Mira \\ Universidade do Vale do Rio dos Sinos (UNISINOS), São Leopoldo, Rio Grande do Sul, Brasil \\ cmira@unisinos.br
}

DOI: http://dx.doi.org/10.21165/el.v46i2.1590

\begin{abstract}
Resumo
As práticas conversacionais constituem um lócus privilegiado para análise dos fenômenos textuais e semânticos envolvidos na compreensão das relações entre linguagem e organização social em grupo. Nesse sentido, torna-se necessária a mobilização de categorias analíticas que abarquem a conversação em suas dimensões textuais e interativas. No âmbito do presente trabalho, as noções de tópico discursivo e de enquadre interativo serão utilizadas para a análise de situações conversacionais de um grupo de afásicos e não afásicos. O nosso objetivo é analisar a relação entre o enquadre interativo e o tópico discursivo em uma interação de um grupo de convivência de afásicos e não afásicos segundo as propriedades do conceito de comunidade de práticas. Pretendemos demonstrar como a gestão tópica é suscetível às configurações do enquadre em um contexto marcado pela especificidade de ser um espaço de convivência e de situações de uso da linguagem.
\end{abstract}

Palavras-chave: afasia; comunidade de prática; interação; tópico.

Interactive frames and discursive topic management in a community of practices of aphasics and non-aphasics

\begin{abstract}
The conversational practices are a privileged locus for the analysis of textual and semantic phenomena involved in understanding the relationship between language and social organization in groups. In this sense, it is necessary to mobilize analytical categories that allows understanding the conversation in its textual and interactive dimensions. Therefore, the discursive topic and the interactive frame notions will be the ones used for the analysis of conversational situations of a group of aphasics and non-aphasics. Our aim is analyzing the relation between the interactive frame and the discursive topic in conversational situations of aphasic and non-aphasic groups according to the properties of the concept of community of practice. In the scope of this work, we expect to demonstrate how topical management is susceptible to the frame settings of the in a context marked by the specificity of being a living space and a space for language use situations.
\end{abstract} Keywords: aphasia; community of practice; interaction; topic.

\section{Introdução}

As afasias são, fundamentalmente, sequelas de um acidente vascular cerebral, de traumatismos cranianos ou de tumores cerebrais que afetam sensivelmente a linguagem em seus vários níveis de constituição e processamento. As afasias podem afetar as formas de articulação e produção dos segmentos fonético-fonológicos, a capacidade de ordenar sintaticamente os elementos dos enunciados, a seleção de itens lexicais em situações comunicativas, os processos semânticos de compreensão e produção (JAKOBSON, 1954; LURIA, 1981). 
No entanto, a definição acima reduz o fenômeno afásico tanto no plano linguístico, quanto no interacional. Reduz porque a questão das afasias não está somente circunscrita nos domínios das alterações estruturais da linguagem humana. A concepção tradicional das afasias tem se servido de uma forte idealização de normalidade da linguagem, sendo os testes metalinguísticos e descontextualizados o terreno propício para a consolidação de uma tradição no campo da Afasiologia.

Dessa forma, as manifestações afásicas em nada se relacionariam com processos que também ocorrem na linguagem não patológica. Além disso, são diagnosticadas a partir de testes de base estruturalista e normativa que têm o pressuposto de que elas são, essencialmente, um problema da ordem de uma metalinguagem estrita, ou seja, um problema de reconhecimento das estruturas e das propriedades da língua tomada como um sistema fechado em si mesmo. Por esse viés, afasias acarretam não só a capacidade metalinguística, mas também a possibilidade de "reflexividade da linguagem que consiste numa reação de reparação e de reconstituição de processos linguísticos" (MORATO, 2001, p. 22).

A afasia não é só um problema de reconhecer e operar as unidades linguísticas, mas também um problema de ordem discursiva e sociocognitiva, pois há um quadro de instabilidades provocado por um evento neurológico e suas implicações, que vão além das sequelas neurocognitivas. Indiscutivelmente, o impacto das afasias repercute no âmbito biopsicossocial. Uma das principais consequências acarretadas pela afasia é o isolamento social que é desencadeado pela interrupção da atividade de dar forma aos conteúdos de nossas experiências e de construir aquilo que é vivido em um sistema simbólico que constitui nossa realidade (VYGOTSKY, 1984; TOMASELLO, 2003).

A partir desses postulados a respeito do fenômeno afásico, nosso objetivo é analisar a relação entre o enquadre interativo e o tópico discursivo em uma interação de um grupo de convivência de afásicos e não afásicos que apresenta as características de uma comunidade de práticas conforme preconizado por Wenger (1998). A noção de enquadre mobilizada neste trabalho é oriunda dos trabalhos realizados por Erickson e Shultz (2002) no campo da Sociolinguística Interacional. Os trabalhos desenvolvidos por Jubran (2006) no âmbito do Projeto Gramática do Português Falado serão a base teóricometodológico da noção de tópico discursivo.

\section{O Centro de Convivência de Afásicos - CCA}

O Centro de Convivência de Afásicos, o CCA, foi concebido como um espaço de interação para o exercício efetivo de práticas cotidianas de linguagem entre os sujeitos afásicos e não afásicos a fim de contribuir para o maior entendimento da condição de afásico e oferecer alternativas para a reintegração social desse sujeito pela convivência e enfrentamento mútuo das inúmeras dificuldades que a afasia implica. Além disso, o CCA também é um espaço de pesquisa e de docência onde pesquisadores e alunos de pósgraduação desenvolvem trabalhos que abrangem a complexa relação entre os aspectos sociais e interativos que envolvem linguagem, cérebro, cognição. Os sujeitos afásicos que frequentam o CCA são encaminhados pelo Departamento de Neurologia, onde recebem todo o tipo de assistência clínica necessária. Os não afásicos que integram o CCA são amigos, familiares e pesquisadores, sendo que estes últimos desenvolvem seus trabalhos no Instituto de Estudos da Linguagem da UNICAMP (MORATO et al., 2002). 
Os encontros desse grupo do CCA acontecem semanalmente, às quintas-feiras, em um prédio especialmente adaptado para tal finalidade, situado nas dependências do Instituto de Estudos da Linguagem da Universidade Estadual de Campinas (IEL/UNICAMP). As atividades do grupo são iniciadas, geralmente, às nove horas, estendendo-se até, aproximadamente, meio dia, desdobrando-se em duas partes principais, mediadas por uma pausa para o café preparado coletivamente: o Programa de Expressão Teatral e o Programa de Linguagem. O fragmento que analisamos neste trabalho é proveniente do Programa de Linguagem.

As atividades do Programa de Linguagem procuram explorar os diversos gêneros e eventos que constituem o uso da linguagem no cotidiano, tais como: diálogos, comentários, narrativas, a exposição e a discussão de notícias de jornais e revistas, as discussões sobre temas sociais e culturais diversos (principalmente de produções culturais como filmes, peças de teatro e obras literárias), comentários sobre o noticiário e a vida política do país, assim como relatos da vida cotidiana e familiar dos membros do grupo. Em outras palavras, tais atividades constituem um espaço marcado por um conjunto de rituais sociais, pelo fortalecimento dos quadros interativos, nos quais os sujeitos podem enfrentar suas dificuldades linguístico-cognitivas e estabelecer processos alternativos de significação, pela evocação de inúmeras práticas de linguagem (MIRA, 2012).

\section{O CCA como uma comunidade de práticas}

Surgido inicialmente no campo da Psicologia Social, o conceito de comunidade de práticas (doravante $\mathrm{CP}$ ) é um componente de uma teoria social de aprendizagem (WENGER, 1998). Em meados da década de 90, esse conceito passa a ser utilizado nas teorias de construção social da identidade, principalmente em trabalhos que investigam a relação entre linguagem e gênero por meio de dados conversacionais (ECKERT; MCCONNELL-GINET, 1992).

Wenger (1998) reformula o conceito, numa crítica aos modelos tradicionais de aprendizagem que requerem dos aprendizes a assimilação de conteúdos em contextos de salas de aulas. A crítica construída pelo autor baseia-se no argumento de que a aprendizagem é um aspecto natural e inevitável da vida, sendo uma prática situada em um contexto histórico e social. É baseado nessa concepção de prática que o autor refina o conceito de comunidade de práticas, atribuindo-lhe três propriedades fundamentais: $i$ ) engajamento mútuo; ii) um empreendimento comum; iii) um repertório de recursos negociáveis compartilhados acumulados ao longo do tempo (WENGER, 1998).

Essas propriedades parecem estar intrinsecamente ligadas à configuração dos encontros semanais do CCA que, devido a sua organização social e suas atividades cotidianas, pode ser considerado como uma comunidade de práticas, uma realidade linguístico-interacional que se relaciona ao incremento e à visibilidade de competência comunicativa de afásicos. Passemos agora à exposição das propriedades de engajamento mútuo, empreendimento comum e de recursos compartilhados.

A primeira delas é o engajamento mútuo (mutual engagement) que diz respeito à disponibilidade dos sujeitos para se reunirem semanalmente em função de um objetivo comum. Segundo Wenger (1998), as práticas de uma comunidade existem pelas relações 
de engajamento mútuo de seus membros, e é por meio desta relação de engajamento que ocorrem os alinhamentos das ações interativas entre os membros

A segunda propriedade do conceito de comunidade de práticas refere-se ao empreendimento comum, isto é, à negociação de objetivos partilhados pelos participantes no curso de uma determinada prática interativa. $\mathrm{O}$ empreendimento comum não é um objetivo compartilhado definido a priori. Pelo contrário, o empreendimento comum é o resultado de um processo coletivo de negociação entre os membros e que reflete o engajamento mútuo. Nas interações do CCA, podemos postular que o empreendimento comum se configura, na realidade, no objetivo que norteia a existência do grupo: a reinserção dos afásicos em situações sociais e cotidianas que promovam o exercício de práticas de linguagem. Esse é o empreendimento comum ao qual os participantes se engajam, sendo um processo dinâmico de (re) atualização das práticas de linguagem a cada novo encontro. Assim, de acordo com Wenger (1998), o empreendimento comum das práticas interativas do CCA, a saber, o de reinserir os afásicos em situações cotidianas de linguagem, é continuamente perseguido por meio de constantes e intensos processos de negociação e de construção conjunta dos sentidos

A última propriedade do conceito de comunidade de práticas, de acordo com Wenger (1998), é o repertório de recursos compartilhados que reflete o histórico das interações dos membros de uma comunidade de práticas. Em outros termos, isto diz respeito aos recursos mobilizados pelos sujeitos na interação para a construção do significado social. Essa é a terceira propriedade que constitui uma comunidade de práticas. Os elementos do repertório são heterogêneos. Os recursos de que os sujeitos lançam mão nas negociações coletivas não são de uma única natureza. Se analisadas separadamente, as negociações podem ser vistas como um conjunto de atividades distintas e incoerentes. Tais recursos, porém, ganham coerência e função definidas quando analisados no contexto de negociação de um objetivo comum.

Os encontros semanais do CCA colocam diferentes sujeitos sociais, com conhecimentos de mundo e experiências sociais distintas, engajados num objetivo comum. O resultado dessa heterogeneidade é a diversidade de posicionamento nas atividades conversacionais, pois a própria conversação é uma prática interativa humana que não detém o caráter de simetria como condição fundamental. A conversação é um processo proposital em que os falantes executam ações coordenadas com a finalidade de atingir um objetivo comum. No entanto, apesar de haver ações coordenadas, o ato de conversar não significa necessariamente processos rigorosamente planejados e simétricos (CLARK, 1996).

\section{O enquadre interativo Debate do CCA}

As atividades do Programa de Linguagem configuram-se como uma reunião. Esse tipo de evento interativo, a reunião, pressupõe o direcionamento das atividades por um dos integrantes e a existência de uma pauta que organiza a ação. Durante o desenvolvimento do evento interativo "reunião", observamos a emergência de diferentes enquadres interativos. Segundo Tannen e Wallat (2002, p. 188-189), o conceito de enquadre interativo refere-se ao 
[...] que está acontecendo em uma interação, sem a qual nenhuma elocução (movimento ou gesto) poderia ser interpretada. Para compreender qualquer elocução, um ouvinte (e um falante) deve saber dentro de qual enquadre ela foi composta: por exemplo, será que é uma piada? Será que é discussão? Algo produzido para ser uma piada, mas interpretado como insulto (certamente podendo significar ambos) pode originar uma briga. [...] A noção interativa de enquadre, então, refere-se à percepção de qual atividade está sendo encenada, de qual sentido os falantes dão ao que dizem. Dado que esse sentido é percebido a partir da maneira como os participantes se comportam na interação, os enquadres emergem das interações verbais e não verbais e são por elas constituídos.

Os participantes do CCA são capazes de perceber as alterações nas estruturas de participação que provocam a emergência de novos enquadres durante a interação. A consequência da emergência desses novos enquadres interativos é a modificação da dinâmica dos turnos e das formas de desenvolvimento do tópico.

As estruturas de participação dizem respeito aos direitos e obrigações dos participantes que são redistribuídos em novas configurações no decorrer da interação. Dessa forma, as estruturas de participação não são constituídas a priori, elas englobam as maneiras de falar, de ouvir, de obter o turno na fala e mantê-lo, de conduzir e ser conduzido, que culminam nas reorientações significativas de posições dos falantes (ERICKSON; SHULTZ, 2002).

As formas de desenvolvimento do tópico dizem respeito a quem o instaura e o conduz mediante a estrutura de participação vigente. Esses dois fatores estão atrelados ao tipo de enquadre interativo que se estabelece durante a reunião. A emergência dos enquadres e a alteração na estrutura de participação e na forma de desenvolvimento do tópico afetam sensivelmente o engajamento dos sujeitos afásicos na atividade, e também a negociação em torno do empreendimento comum do grupo. No âmbito deste trabalho, analisaremos a emergência e a configuração interativa do enquadre Debate.

A principal característica do enquadre Debate é a regularidade do desenvolvimento interacional proporcionada pelo direcionamento claro dado pelas pesquisadoras, direcionamento este que pode ser percebido pelos tipos recorrentes de ações praticadas por elas: a introdução de um tópico previamente selecionado, seguido de esclarecimentos didáticos sobre o tema para aqueles participantes que não o conhecem muito claramente e a condução da discussão por meio da distribuição de turnos.

Vale também ressaltar outro recurso compartilhado que tem grande relevância na estruturação das interações: o conhecimento prévio sobre as estruturas de participação do enquadre Debate. Em função de uma rotina interativa já consolidada, existe um conhecimento implícito das formas de agir que os enquadres interativos demandam. Os sujeitos reconhecem que a estrutura do enquadre Debate requer que suas ações, principalmente o direito à palavra e as formas de obtê-la, sejam organizadas a fim de permitir a exposição dos argumentos e o posicionamento frente ao tema.

A adesão dos participantes às práticas está relacionada ao tipo de enquadre comunicativo, à relevância do tópico conversacional na rotina do grupo, e também aos conhecimentos compartilhados necessários para o desenvolvimento do tipo de interação que o enquadre requer. Engajar-se significa, sobretudo, participar de atividades de alinhamento de ponto de vista, de produção de argumentos, de negociação. 
O resultado do engajamento dos sujeitos no enquadre Debate é a construção conjunta dos sentidos. Este processo, na realidade, corresponde ao empreendimento comum no qual os sujeitos estão engajados, isto é, participar de situações cotidianas de uso da linguagem. No enquadre discussão, a exposição dos argumentos, o desenvolvimento do tópico e o posicionamento dos sujeitos frente à polêmica da discussão são as atitudes concretas que revelam o processo de reintegração dos sujeitos afásicos em situações cotidianas de uso da linguagem.

Segundo Vion (1992), o debate constitui um tipo de interação regida pelos princípios da cooperação e da competitividade. O equilíbrio entre dois elementos produz dois tipos distintos de discussão: as discussões cooperativas orientadas na busca de consensos e as discussões conflituosas orientadas na disputa e exacerbação de diferenças.

\section{Procedimentos metodológicos}

O recorte dos dados analisados foi realizado a partir do segmento tópico e das formas de condução dos turnos, no intuito de analisar a configuração interativa a partir dessas duas categorias conversacionais. Especificamente, os excertos apresentados neste artigo são provenientes do enquadre Debate.

O enfoque textual-interativo foi utilizado em nossas análises para contemplar os fenômenos relacionados ao turno conversacional e ao tópico discursivo. A escolha do enfoque textual-interativo é justificada em função da colaboração entre os interlocutores na interação oral, o partilhar de conhecimento entre ambos e o esforço e a disposição para produzir inferências e negociar os sentidos (KOCH; PENNA, 2006).

O sistema de notação utilizado na transcrição dos dados tem como base as notações já utilizadas nos estudos do projeto NURC e as marcações propostas por Marcuschi (1998) para a análise de interações orais, acrescidas de alguns elementos que salientam aspectos importantes para a análise das situações interativas envolvendo indivíduos afásicos, como a presença de semioses não-verbais (aspectos proxêmicos, expressão facial, atitudes corporais, gestualidade, direcionamento do olhar, etc.), fundamentais para a compreensão da dinâmica interativa das atividades do CCA. Para garantir a melhor compreensão dos dados, adotamos alguns procedimentos que valem ser aqui ressaltados:

a) a identificação dos participantes do CCA é feita a partir das iniciais do nome e do sobrenome. No caso dos afásicos, as iniciais estão negritadas apenas para a visualização dos dados;

b) o texto da transcrição é apresentado em sistema ortográfico modificado; em alguns casos, torna-se necessária a transcrição fonética;

c) no caso de locução, são usadas as iniciais em letras maiúsculas dos participantes; quando se trata de suas condutas não-verbais ou de significação não-verbal, a descrição de tais aspectos segue entre parênteses. 


\section{Análise de um episódio interacional}

As atividades do Programa de Linguagem analisadas neste trabalho tiveram como tema a questão, muito polêmica na época, da quebra de um contrato publicitário que envolvia o sambista Zeca Pagodinho e duas famosas marcas de cerveja. Esse acontecimento teve repercussão nacional pelo fato de que uma das marcas de cerveja ofereceu uma grande quantia de dinheiro para que o sambista imediatamente deixasse de fazer a propaganda da concorrência, além de arcar com o ônus da rescisão contratual.

Houve um amplo debate, veiculado amplamente nos meios de comunicação de massa, a respeito da conduta do cantor, o que possibilitou a emergência de duas posições argumentativas: uma contra Zeca Pagodinho, por sua atitude de ter violado um contrato comercial, mas também valores éticos e morais; e uma outra, favorável à atitude do cantor, por se caracterizar como uma estratégia comercial ousada e lucrativa para uma das marcas de cerveja e também para o cantor. Todos os desdobramentos desse debate foram alvos de uma intensa cobertura da imprensa. Houve, inclusive, veiculação de uma peça publicitária da marca de cerveja cujo contrato publicitário foi rompido pelo sambista, uma espécie de réplica do episódio ocorrido.

Nesse encontro, os integrantes do grupo, após os cumprimentos habituais e os preparativos do café, iniciam as atividades do programa de linguagem com o relato da pesquisadora EM a respeito de uma reportagem, lida por ela, que tratava da questão da quebra de contrato do sambista com a marca de cerveja. $\mathrm{O}$ relato da pesquisadora era na realidade uma indagação aos integrantes do grupo visando saber se eles tinham conhecimento deste fato e, dessa forma, permitir o engajamento do grupo na conversação. Ao mesmo tempo em que a pesquisadora EM faz essa indagação, ela já instaura o tópico da interação que demanda um posicionamento dos integrantes a respeito da questão da quebra de contrato e, consequentemente, o programa de linguagem adquire características e contornos claros de um debate.

O enquadre Debate requer uma participação ativa na interação, ao exigir que os participantes tomem uma posição argumentativa em relação ao tema da pauta proposta pela pesquisadora. As ações desenvolvidas no debate estão atreladas a sua estruturação, isto é, à regularidade no sistema de trocas de turnos, que caracteriza a estrutura de participação do enquadre, e à simetria do desenvolvimento do tópico. Procuraremos mostrar aqui como as estruturas deste enquadre forjam as dinâmicas dos turnos e o desdobramento do tópico da interação.

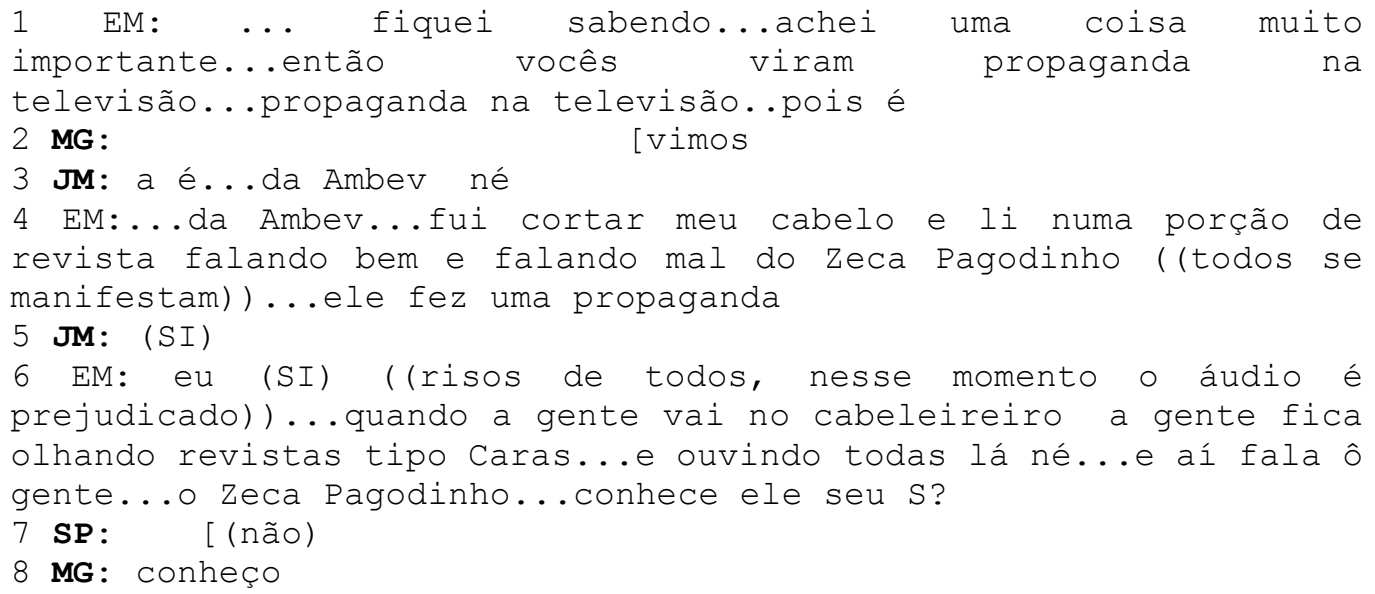




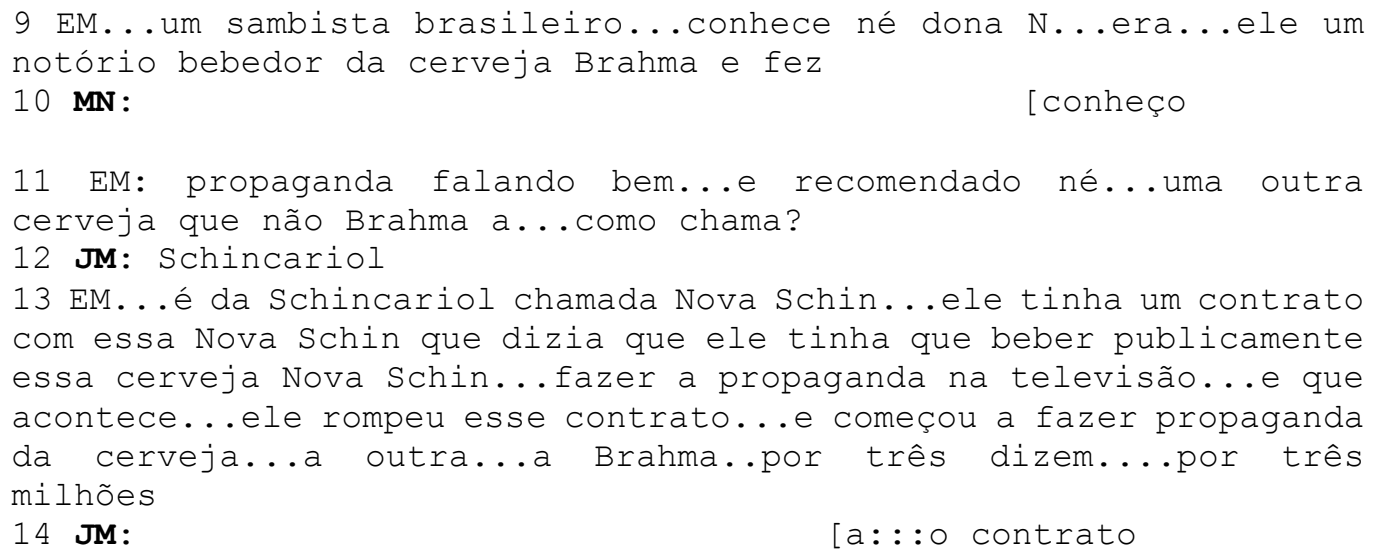

Segmento 1: (1-14) - Instauração do tópico.

No segmento 1-14, temos basicamente a introdução do tópico que, conforme veremos nos segmentos abaixo, desencadeia um debate acerca de valores éticos e morais envolvidos na questão noticiada pela revista que EM menciona (linhas 1 e 4). Na linha 2, a participante afásica $\mathrm{MG}$ reconhece prontamente a questão relatada por EM, sem ser diretamente interpelada na introdução do tópico. A posição de interesse de MG pelo debate que o tópico introduzido por EM suscita manifesta-se de forma bem visível no decorrer do encontro. Um dos primeiros sinais do engajamento de MG ao debate pode ser visto em seu primeiro turno, transcrito na linha 2 .

Assim que EM introduz o tópico da interação, representado pelo sintagma nominal "propaganda de televisão", MG insere seu turno durante uma micro pausa no turno de EM, porém sem tomá-lo (linha 2). Dessa forma, MG reconhece o local mais propício para a sua inserção de turno, que não chega a ser uma sobreposição. $O$ turno inserido por EM instaura o tópico que dá origem às estruturas de participação demandadas pelo enquadre interativo Discussão. Nesse tipo de turno, devem ser evitadas sobreposições que causem rupturas (o de instauração do tópico). Na linha 3, JM reconhece e realiza a complementação do conteúdo semântico do tópico instaurado por EM.

$\mathrm{Na}$ linha 4, EM detalha qual é a questão da polêmica relacionada ao sambista, de acordo com o que ela havia lido na revista. Esse turno de EM é a integração de um conjunto referencial lançado anteriormente (na linha 1). É possível perceber na linha 4, quando após dizer o nome do sambista envolvido na polêmica (Zeca Pagodinho), todos os participantes manifestam-se simultaneamente. O turno da linha 4 apresenta os enunciados que são concernentes ao conjunto de referentes que foram introduzidos anteriormente na conversa, ou seja, neste turno ocorre a integração de segmentos textuais que exemplificam os referentes enunciados na linha 1.

É a partir deste momento que efetivamente é possível perceber o engajamento à discussão, que no caso se traduz em debater os valores morais envolvidos no episódio da quebra de contrato. Em outras palavras, esse é o momento em que a atividade do programa de linguagem é decidida e o tópico é instaurado. Essa função, aqui, é desempenhada por um integrante não afásico. É frequente que EM inicie as atividades do programa, instaure o tópico e comece a distribuir os turnos por meio de perguntas, o que gera, muitas vezes, uma dinâmica de turnos baseada na estrutura de pares adjacentes. Isso 
pode ser explicado em função da categorização social dos participantes na estrutura social do grupo.

Apesar de os sujeitos afásicos demonstrarem autonomia para manipular os turnos e agir no desenvolvimento do tópico, a função de gerenciar as atividades do programa, ou seja, conduzir o encontro, instaurar o tópico e distribuir e manter a dinâmica de turnos, cabe, em geral, aos participantes que são pesquisadores ligados à instituição, não afásicos. Vale ressaltar que devemos considerar em nossos dados os papéis sociais dos membros do CCA, o que, sem dúvidas, influencia diretamente as interações, especificamente na gestão do tópico. Isso pode ser explicado pelo status institucional do CCA, ou seja, a ligação hierárquica do centro de convivência com a Universidade Estadual de Campinas.

Ainda no momento de instauração do tópico, após as inserções de turnos de MG e JM, a pesquisadora EM continua a relatar a maneira como teve conhecimento do episódio da quebra de contrato (linha 6). Ao fazer tal relato, EM realiza também algumas distribuições de turnos, com perguntas diretas a determinados participantes, como podemos observar no segmento (linhas 6-10). Isso fica evidente nas linhas 9 e 10, quando EM indaga diretamente $\mathrm{MN}$, que responde logo após uma micro pausa no turno de EM.

MG e JM demonstram ter conhecimento prévio acerca do tópico, e, assim, inserem seus turnos, os demais participantes ainda não fazem inserções de turnos. Para estender o tópico a todos os integrantes, EM adota a estratégia de dirigir alguns turnos para assegurar a participação de todos, pois o desenvolvimento do tópico ocorre em função de um processo que envolve de maneira colaborativa os participantes da interação. Tal processo é baseado numa gama de fatores contextuais e de background de informações prévias e de visões de mundo que são entendidos ou compartilhados durante o ato conversacional (JUBRAN, 2006).

A respeito das inserções de turnos de MG e JM, devemos salientar que ocorrem de forma mais autônoma e que obedecem ao fluxo do desenvolvimento do tópico. Essa autonomia, que pode ser percebida nas inserções de turno, ocorre, parcialmente, em função do tempo de participação no grupo e das experiências pessoais por eles vividas antes do episódio que culminou na afasia. Por exemplo, MG era uma dona de agência de viagens e sua rotina profissional demandava situações de uso da linguagem em que era requerido o conhecimento do funcionamento das regras da conversa de antecipar ou esclarecer informações que surgem durante o fluxo do tópico. JM era comerciante e tinha uma rotina de práticas conversacionais semelhante à rotina de MG. Conforme argumenta Hanks (2008), esses são os aspectos estruturados das práticas, trazidos pelos sujeitos a partir de experiências prévias, e que moldam significativamente suas ações, emergindo em novas práticas comunicativas.

Tais conhecimentos das particularidades da conversa (seja em relação à forma de transição de turnos ou às formas de desenvolvimento do tópico) não deixam de transparecer nas interações de MG e JM. Pelo fato de conhecerem tais particularidades e colocá-las em prática (conforme nos mostra o segmento 1-4), seus papéis sociais dentro do CCA são construídos a partir disso. Em outras palavras, a imagem que MG e JM projetam para o grupo é de participantes ativos que emitem opiniões próprias a respeito de diversas polêmicas. O reconhecimento dessas imagens, que são construídas antes e depois do ingresso no CCA e constantemente exibidas e reestruturadas nas atividades do programa de linguagem, exerce influência direta na forma como os participantes aderem à interação e, consequentemente, nas formas de desenvolvimento do tópico. 


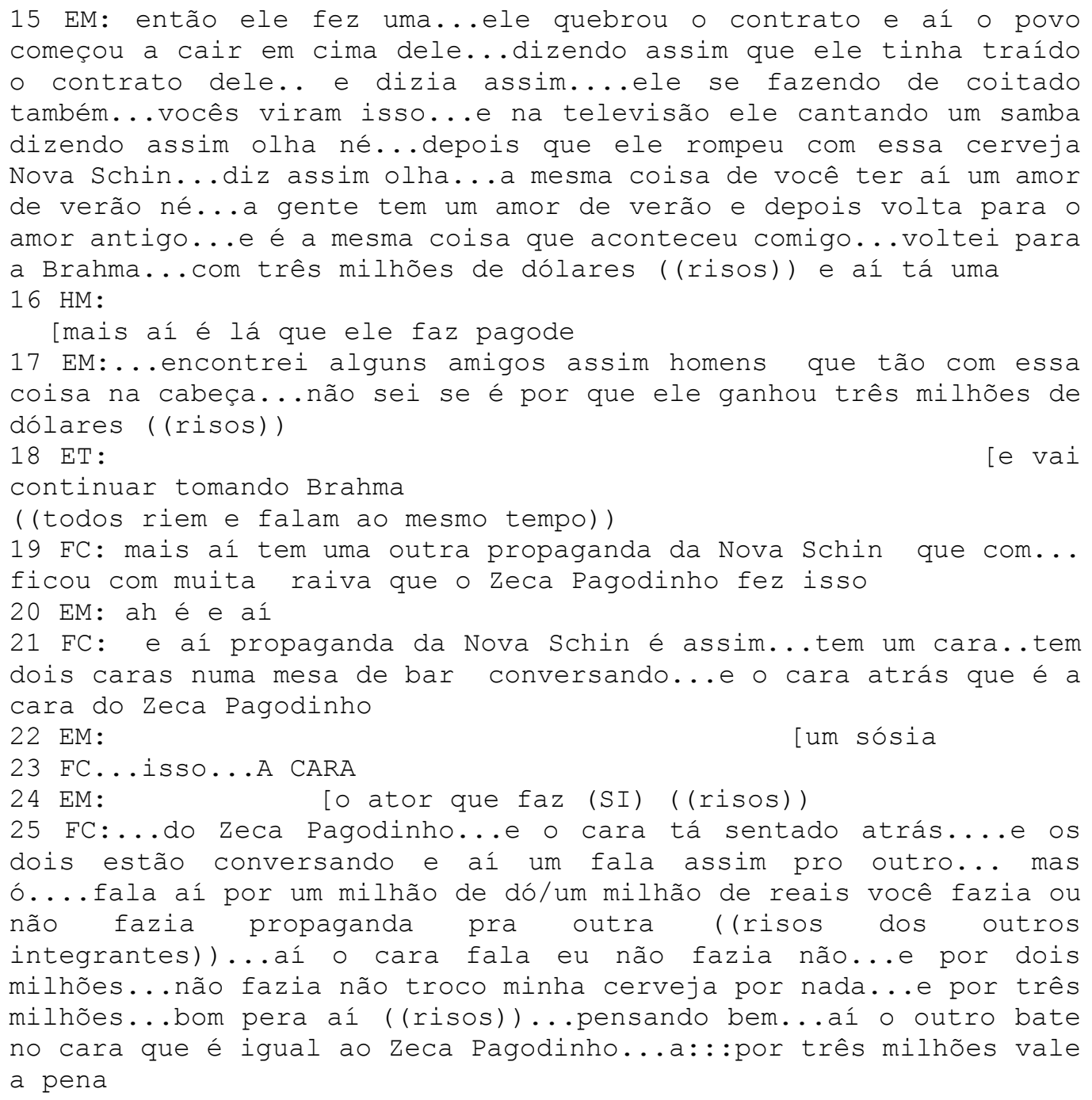

Segmento 2: (15-25) - Especificação das questões geradas pelo tópico.

Para que ocorra um debate frutífero, é necessário que haja subsídios concretos para os participantes embasarem seus argumentos e contribuírem para que a questão do debate seja expandida e, consequentemente, que o tópico seja desenvolvido. O segmento 15-25 apresenta a pontualização do tópico instaurado por EM no início da atividade do programa de linguagem (linha 4: EM:...da Ambev...fui cortar meu cabelo e li numa porção de revista falando bem e falando mal do Zeca Pagodinho ((todos se manifestam))...ele fez uma propaganda).

O segmento acima apresenta focalização, proeminência desse conjunto referencial no curso da interação. Ainda é possível observar que esse segmento traz vários turnos elaborados apenas pelas pesquisadoras que servem para especificar ainda mais detalhes do tópico (a descrição do episódio da quebra de contrato, a repercussão do fato e o valor monetário pago ao sambista para fazer o anúncio da outra marca de cerveja). Os turnos deste segmento são longos e simétricos, sobrepostos por turnos inseridos fora de micro pausas, mas que são nucleares, conforme a tipologia sugerida por Galembeck (1997), por trazerem elementos referenciais que contribuem para o desenvolvimento do tópico. 
Em termos de análise das funções desempenhadas por sujeitos afásicos e não afásicos no intercâmbio da manipulação das estruturas conversacionais, é possível observar, nesse dado, que as funções de definição ou de centração tópica ficam, de maneira predominante, a cargo de integrantes não afásicos. Isso ocorre fundamentalmente pelo fato de que são as pesquisadoras que definem a pauta do encontro, ou seja, definem que tipo de atividade será desenvolvida e, dessa forma, fica delineado o enquadre interativo do encontro.

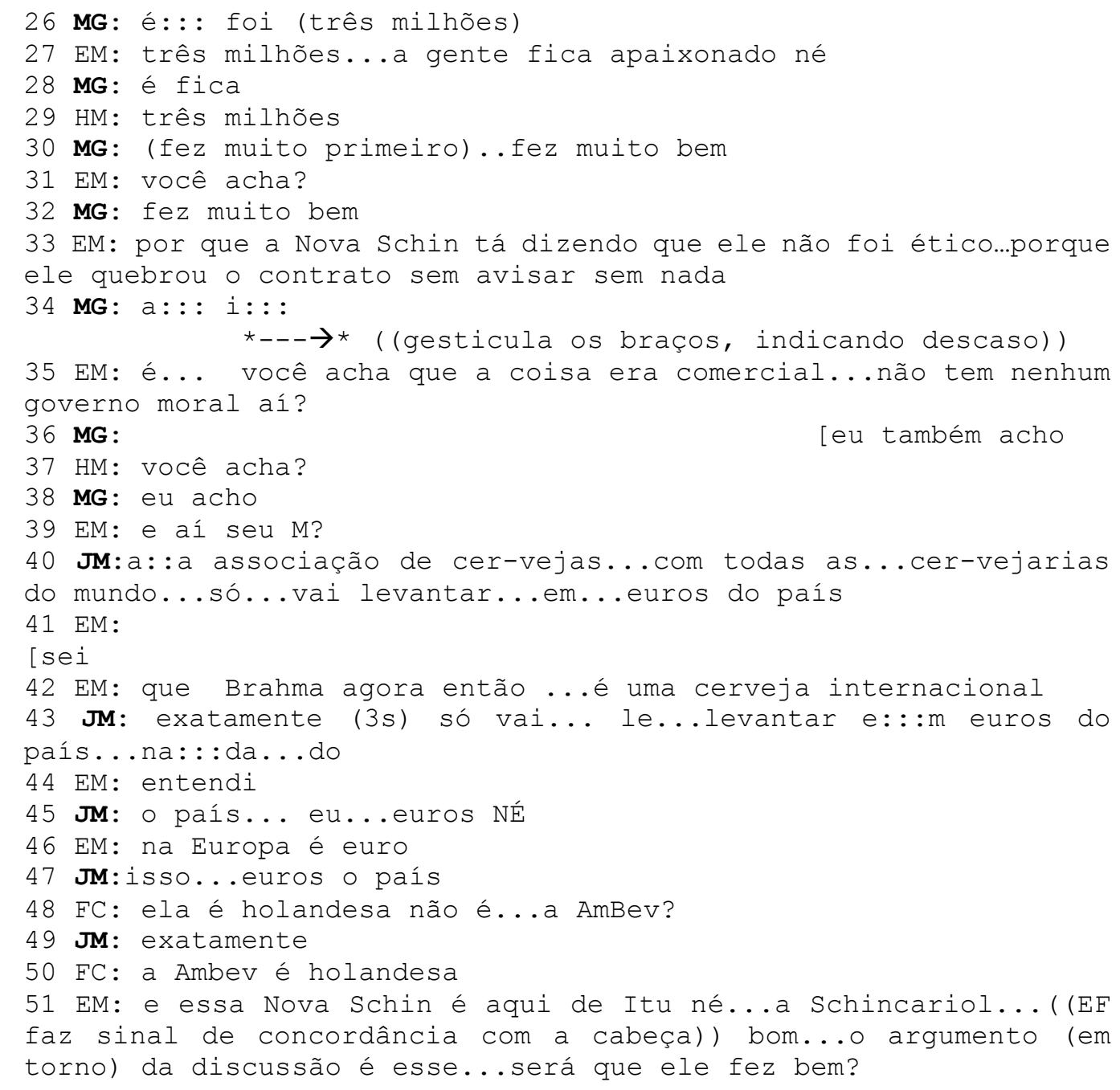

Segmento 3: (26-51) - Discussão das questões.

Após a pesquisadora $\mathrm{FC}$ descrever um anúncio publicitário feito pela empresa que foi o pivô da quebra de contrato (linha 25), MG dá início ao cerne do debate, ao reiterar o valor mencionado por $\mathrm{FC}$ e se posicionar frente ao debate de valores morais que se estabelece pelo desenvolvimento do tópico, ou seja, se o sambista agiu corretamente ao quebrar o contrato por determinada soma de dinheiro (cf. o seguimento 26-31). A transição de turnos nesse segmento ocorre por meio da estrutura de pares adjacentes, sem sobreposições e obedecendo aos LRT (Lugares Relevantes de Transição de Turno), principalmente após sinais prosódicos. Na linha 27, após o marcador conversacional "né”, e na linha 31, pela entonação descendente da interrogação. A estrutura de pares adjacentes favorece uma transição de turnos sem sobreposições, e este contexto para a transição de 
turnos é reconhecido por MG, pois ela insere seus turnos justamente após as marcas prosódicas mencionadas acima.

Na linha 33, a pesquisadora EM questiona diretamente MG se ela ainda sustenta sua posição argumentativa frente ao embate ético da quebra de contrato. A partir desta linha é lançada a questão cerne que envolve todo o debate, conforme se observa no enunciado de EM (linha 35: é... você acha que a coisa era comercial...não tem nenhum governo moral aí?). Na sequência, há a reiteração da questão do debate por meio de uma transição de turnos que ainda segue a estrutura de pares adjacentes. Mesmo com as indagações de EM e HM (linhas 35 e 37), MG mantém sua posição. Tal forma de engajamento de MG na discussão pode ser considerada não só uma mera reiteração da posição moral e argumentativa de MG para esta questão, mas também uma forma de posicionamento de sua imagem perante o grupo. Ao considerarmos que o CCA se configura como um grupo socialmente organizado, a atitude de $\mathrm{MG}$ frente ao debate pode ser vista tanto como um exercício de argumentação, quanto como uma exibição (e legitimação) de seu estatuto de participante no grupo, constituído a partir do seu histórico de participação e da heterogeneidade da constituição do CCA.

Após o tópico ser instaurado e a questão do debate ter vindo à tona, EM novamente direciona os turnos, para que outros participantes, além de MG, posicionem-se (linha 39). No entanto, ocorre uma digressão tópica. Nesse caso, outra questão surge frente à questão principal do debate. Após ser indagado por EM para posicionar-se frente à questão principal do debate, JM lança outra questão, que ainda está inserida dentro do referente supertópico, porém, ocorre o surgimento de um subtópico. Ao invés de argumentar a respeito da questão do debate, isto é, se a conduta do sambista é justificada pela soma de dinheiro paga, JM instaura o subtópico "nacionalidade da cervejaria” (linha 40).

A colocação de JM modifica o fluxo do tópico, pois coloca em foco um fato que vai além do debate de valor da questão. Em outras palavras, o subtópico de JM é derivado do supertópico instaurado e debatido principalmente por EM e MG, porém não demanda a estrutura interativa do enquadre Debate, que requer um movimento argumentativo. Especificamente, no segmento 35-51 há uma mudança no fluxo interativo que influi tanto no desenvolvimento do tópico, quanto nas formas de transição de turnos. O subtópico instituído por JM coloca momentaneamente em foco uma questão vai além da discussão de valores éticos do supertópico.

É possível observar que, durante a transição dos turnos, o desenvolvimento do subtópico ocorre de forma distinta do padrão de transição observado no supertópico. Enquanto no supertópico é predominante a estrutura de pares adjacentes, com a pesquisadora EM direcionando os turnos, no subtópico observam-se turnos que são finalizados após turnos antecedentes, sem a ocorrência de sobreposições ou turnos permeados por micro pausas. A exceção é o turno de JM (linha 43), onde há uma pausa de 3 segundos, seguida de dois alongamentos vocálicos. A partir da linha 41 até a linha 49, há turnos assimétricos. A assimetria se caracteriza pelo fato de o desenvolvimento do tópico ficar a cargo de um dos locutores, enquanto o outro apenas "segue", ou "vigia" seu interlocutor (GALEMBECK, 1997). No segmento acima, os outros participantes, que não são afásicos, inserem turnos que "seguem" o conjunto de referentes lançado por JM na linha 40. Isso pode ser considerado uma mudança no plano intratópico e na dinâmica de turnos. 
O que salientamos na análise desse segmento é que o subtópico introduzido e conduzido por JM provoca a emergência de aspectos associados ao tempo real da produção do enunciado e da interação, o que acarreta a capacidade de os interactantes perceberem e prestarem atenção uns aos outros; a emergência pode ser facilmente concebida em níveis temporais diferentes. No caso desse segmento, temos a mudança de um debate entre dois participantes, conduzido pela pesquisadora EM, para um contexto em que há o conhecimento compartilhados entre os interactantes.

Ainda que, aparentemente, o CCA apresente uma configuração social definida previamente pelos papéis sociais de seus integrantes, não é possível estabelecer a priori quem determina as estruturas interativas ou direciona integralmente as situações conversacionais. Por exemplo, nesse segmento, o subtópico é instaurado por um afásico e os participantes não afásicos passam a colaborar com o seu desenvolvimento. Esse contexto interativo, que ocorre devido ao surgimento do subtópico e da mudança da dinâmica de turno, também demonstra que os papéis interativos são dinâmicos e não estão atrelados totalmente à configuração e aos papéis sociais dos integrantes do CCA.

\section{Considerações finais}

No âmbito do episódio interacional analisado neste trabalho, é possível constatar que o tópico é um fator da conversação responsável pela construção partilhada dos sentidos na interação, o que é importante nos dados do CCA devido à sua configuração de uma comunidade de práticas. Por isso, o tópico, no enquadre Debate, possibilita o engajamento dos participantes e a negociação conjunta do objetivo comum por meio de recursos compartilhados.

Podemos considerar que a adesão ao Programa de Linguagem do CCA ocorre em função de fatores semânticos e pragmáticos que sustentam o envolvimento da conversação. $\mathrm{O}$ enquadre interativo Debate exemplifica que as práticas conversacionais do CCA estão mais relacionadas ao seu conteúdo do que à forma linguística dos enunciados conversacionais. Dessa forma, o enquadre analisado tem sua organização pautada no tópico discursivo, que, por sua vez, define as formas de trocas de turno. Em relação aos turnos, os movimentos de sobreposição, finalização e reconhecimento dos momentos específicos de inserção ocorrem em função da configuração interativa do enquadre, demandada pelo tópico no contexto de uma comunidade de práticas.

O fragmento interacional que analisamos demonstra que a progressão tópica (produto do engajamento comum do grupo) ocorre na medida em que os aspectos semânticos e textuais da interação passam a ter sentido para os participantes do grupo. E esse sentido, que é conjuntamente construído na interação, configura-se como um dos principais elementos responsáveis pelo pertencimento a um grupo social. Considerando a especificidade de o CCA ser um espaço de convivência e de práticas de linguagem, é possível observar, no dado apresentado neste trabalho, que não há ausência ou presença incipiente do turno conversacional ou do tópico discursivo, ainda que encontremos formas diferenciadas do uso destas categorias conversacionais. Diferenciadas não no sentido de serem totalmente alteradas ou deturpadas pelas afasias, mas diferenciadas justamente pelo fato de que o CCA é um grupo socialmente organizado que apresenta as propriedades estruturais de uma comunidade de práticas. 


\section{REFERÊNCIAS}

CLARK, H. Using Language. Cambridge: Cambridge University Press, 1996.

ECKERT, P.; MC-CONNELL-GINET, S. Think practically and look locally: Language and gender as community-based practice. In: Annual review of Anthropology, s/1., s/ed., v. 27, p. 461-490, 1992.

ERICKSON, F.; SHULTZ. E. O "quando" em um contexto: questões e métodos na análise da competência social. In: RIBEIRO, B. T.; GARCEZ, P. M. Sociolinguística Interacional, 2. ed. São Paulo: Loyola, 2002. p. 125-142. (Originalmente publicado em Ethnography and Language, 1981).

GALEMBECK, P. O turno conversacional. In: PRETI, D. (Org.). Análise de textos orais. 3. ed. São Paulo: Humanitas, 1997. p. 88-94.

HANKS, W. O que é contexto? In: BENTES, A. C.; REZENDE, R. C.; MACHADO, M. A. R. (Org.). Língua como prática social: das relações entre língua cultura e sociedade a partir de Bourdieu e Bakhtin. São Paulo: Cortez, 2008. p. 169-201.

JAKOBSON, R. Linguística e comunicação. São Paulo: Cultrix, 1981 [1954].

JUBRAN, C. C. O tópico discursivo. In: JUBRAN, C. C. A.; KOCH, I. G. V. (Org.). Gramática do português falado culto no Brasil: a construção do texto falado. v. 1. Campinas: Editora da UNICAMP, 2006. p. 89-132.

KOCH, I. G. V.; PENNA, M. A. O. Construção e Reconstrução de objetos-de-discurso: manutenção tópica e progressão textual. In: Cadernos de Estudos Linguísticos, Campinas, v. 48, n. 1, p. 23-31, jan./jun. 2006.

LURIA, A. R. Fundamentos de Neuropsicologia. São Paulo: EDUSP, 1981.

MARCUSCHI, L. A. Análise da Conversação. São Paulo: Ática, 1998.

MIRA, C. C. C. R. Afasia e interação: uma análise da dinâmica de turnos e da gestão do tópico nas práticas conversacionais de sujeitos afásicos e não-afásicos. $2012.166 \mathrm{f}$. Tese (Doutorado em Linguística) - Instituto de Estudos da Linguagem, Universidade Estadual de Campinas, Campinas, 2012.

MORATO, E. M. Neurolinguística. In: MUSSALIM. F.; BENTES, A. C. (Org.). Introdução à Linguística: domínios e fronteiras. v. 2. São Paulo: Cortez, 2001. p. 143170.

MORATO, E. M. et al. Sobre as afasias e os afásicos. Subsídios teóricos e práticos elaborados pelo Centro de Convivência de Afásicos. Campinas: Editora da UNICAMP, 2002.

TANNEN. D.; WALLAT. C. Enquadres interativos e esquemas de conhecimento em interação: exemplos de um exame/consulta médica. In: RIBEIRO, B. T.; GARCEZ, P. M. Sociolinguística Interacional. 2. ed. São Paulo: Loyola, 2002. p. 153-174. (Originalmente publicado em Social Psychology Quarterly, nº 50, 1987).

TOMASELLO, M. Origins of human communication. Cambridge: MIT Press, 2003.

VION, R. La communication verbale: analyse des interactions. Paris: Hachette, 1992.

VYGOTSKY, L. S. A Formação Social da Mente. São Paulo: Martins Fontes, 1984. 
WENGER, E. Communities of practice. Learning, meaning and identity. Cambridge: Cambridge University Press, 1998.

Recebido em: 18/08/2016

Aprovado em: 10/01/2017 
ANEXO

\begin{tabular}{|c|c|c|}
\hline OCORRÊNCIAS & SINAIS & EXEMPLOS \\
\hline $\begin{array}{l}\text { Incompreensão de palavras ou } \\
\text { segmentos }\end{array}$ & (SI) & $\begin{array}{l}\text { Então é...olha deve ta com } \\
\text { (SI)...deixa eu ver... }\end{array}$ \\
\hline Hipótese do que se ouviu & (hipótese) & Aqui (livro)...ah \\
\hline $\begin{array}{l}\text { Truncamento ou interrupção } \\
\text { brusca }\end{array}$ & / & Dia pri/trinta e um de julho \\
\hline Entonação enfática & Maiúscula & afaSIAS \\
\hline $\begin{array}{l}\text { Prolongamento de vogal e } \\
\text { consoante }\end{array}$ & $\begin{array}{c}\text { (podendo aumentar } \\
\text { de acordo com a } \\
\text { duração }\end{array}$ & $\begin{array}{l}\text { Agora...a:...a Ida Maria que } \\
\text { pesquisou }\end{array}$ \\
\hline Silabação & - & Ser-vi-do-res \\
\hline Interrogação & $?$ & Pra quem você mandou isso? \\
\hline Qualquer pausa & $\ldots$ & $\begin{array}{l}\text { Ela veio qui... perguntar... veio se } \\
\text { instruir }\end{array}$ \\
\hline $\begin{array}{l}\text { Pausas prolongadas (medidas em } \\
\text { segundos) }\end{array}$ & $(3 s)$ & $\begin{array}{l}\text { MS: ã::::ham ( } 3 \mathrm{~s}) \text { centro } \\
\text { indica } 3 \text { segundos de pausa }\end{array}$ \\
\hline $\begin{array}{l}\text { Comentários do transcritor e } \\
\text { designações gestuais }\end{array}$ & $(($ minúscula $))$ & Isso não... ((risos)) \\
\hline $\begin{array}{l}\text { Comentários que quebram a } \\
\text { sequência temática da exposição }\end{array}$ & - & $\begin{array}{l}\text { Maria Éster... - . dá pra... ta longe aí } \\
\text { né... pequenininho... eu também não } \\
\text { enxergo direito...- Oliveira da } \\
\text { Silva... e ela também é coordenadora }\end{array}$ \\
\hline Sobreposição & $\begin{array}{l}\text { [ apontando o local } \\
\text { onde ocorre a } \\
\text { sobreposição }\end{array}$ & $\begin{array}{l}\text { MG: Nova Iguaçu } \\
\text { JM: } \quad[\text { ah }\end{array}$ \\
\hline Simultaneidade de vozes & $\begin{array}{c}{[[\text { apontando o local }} \\
\text { onde ocorre a } \\
\text { simultaneidade }\end{array}$ & $\begin{array}{l}\mathrm{MN}:[[\text { eu falava.. mas } \\
\mathrm{NS}:[[\text { quatro ano.. deixa } \\
\text { (indica que duas conversas ocorrem } \\
\text { simultaneamente) }\end{array}$ \\
\hline $\begin{array}{l}\text { Indicação de que a fala foi } \\
\text { retomada }\end{array}$ & ... no início & $\begin{array}{l}\text { EM: a gente ta mandando pros } \\
\text { coordenadores e eles tão colocando } \\
\text { onde... } \\
\text { EM: ...nas bibliotecas... }\end{array}$ \\
\hline $\begin{array}{l}\text { Citações literais ou leituras de } \\
\text { textos }\end{array}$ & “ $"$ & $\begin{array}{l}\text { aqui... "vimos por meio dessa... } \\
\text { desta agradecer o envio dos livros..." }\end{array}$ \\
\hline $\begin{array}{l}\text { Indicação e continuidade de gestos } \\
\text { significativos, com a descrição de } \\
\text { gestos }\end{array}$ & $\begin{array}{c}\text { * início e fim } \\
\text { do gesto* } \\
*_{-}^{*} \\
\text { continuidade gestual }\end{array}$ & $\begin{array}{l}\text { NS: i::xi... faz tempo aqui } \\
\text { com o dedo }))\end{array}$ \\
\hline
\end{tabular}

Fonte: Elaboração própria a partir de Marcuschi (1998) 